\title{
Visual Search for Letters in the Right Versus Left Visual Hemifields
}

\author{
Elena S. Gorbunova' and Maria V. Falikman ${ }^{1,2}$ \\ 1 School of Psychology, National Research University Higher School of Economics (HSE) \\ ${ }^{2}$ Russian Presidential Academy of National Economy and Public Administration
}

\section{KEYWORDS}

visual search

visual attention

left/right visual field asymmetry

word superiority effect

\section{ABSTRACT}

The current study investigated the relationships between attention, word processing, and visual field asymmetries. There is a discussion on whether each brain hemisphere possesses its own attentional resources and on how attention allocation depends on hemispheric lateralization of functions. We used stimuli with lateralized processing in an attentional task presented across the two visual hemifields. Three experiments investigated the visual search for a prespecified letter in displays containing words or nonwords, placed left and right to fixation, with a variable target letter position within the strings. In Experiment 1, two letter strings of the same type (words or nonwords) were presented to both visual hemifields. In Experiment 2, there was only one letter string presented right or left to fixation. In Experiment 3, two letter strings of different type were presented to both hemifields. Response times and accuracy data were collected. The results of Experiment 1 provide evidence for letter-by-letter search within a word in the left visual field (LVF), within a nonword in the right visual field (RVF), and for position-independent access to letters within a nonword in LVF and within a word in RVF. Experiment 3 produced similar results except for letter-by-letter search within words in RVF. In Experiment 2, for all types of letter strings in both hemifields, we observed the same letter-by-letter search. These results demonstrate that presence of stimuli in both one or two hemifields and the readiness to process a certain string type might contribute to the search for a letter within a letter string.

\section{INTRODUCTION}

Among the important issues in studies of high-level human vision are the mechanisms of reading and lexical processing, and their interaction with attention. This issue can be addressed through an investigation of the role and mechanisms of visual attention in the processing of embedded stimuli, such as letters within words (e.g., Falikman, 2011; Fine, 2001; Johnston \& McClelland, 1974; Salvemini, Stewart, Purcell, \& Pinkham, 1998) and words within sentences (Barber, Ben-Zvi, Bentin, \& Kutas, 2011; Potter, Nieuwenstein, \& Strohminger, 2006). What is special about lexical stimuli is the functional specialization of the human brain, contributing to visual field asymmetries for spatially distributed stimuli.

Visual field asymmetries refer to differences in the processing of stimuli presented in different parts of the visual field. There are three types of visual field asymmetries reported in the literature: (a) left/ right, (b) temporal/nasal, (c) and upper/lower (e.g., Michael \& Ojeda,

Corresponding author: Elena Gorbunova, School of Psychology, National Research University Higher School of Economics, Moscow, Russia. e-mail:gorbunovaes@gmail.com 
2005). Left/right asymmetries are probably the most complex ones, with a number of contributing factors, such as hemispheric modes of processing, attentional system asymmetry in the brain, lateralization of language in the brain, and language-specific reading practices.

According to Bever (1975), left-right cerebral asymmetries of mental functions reflect two modes of processing in the human brain: analytic, more typical for the left hemisphere, and holistic, more represented in the right hemisphere. Although in both auditory and visual language processing both modes of processing and both hemispheres are involved (Lindell, 2006), specialized language areas are lateralized to the left in the majority of the right-handed population.

Regarding visual perception and attention, this distinction could also be understood in terms of global versus local information processing (Navon, 1977). It has been demonstrated that, despite the general global superiority described by Navon, the left hemisphere tends to local processing, whereas the right hemisphere rather tends to global processing (Kimchi \& Merhav, 1991; for a more detailed discussion, see also Kimchi, 2015).

One of the most important questions is whether both hemispheres participate in selective attention and whether they contribute equally. The first positron emission tomography (PET) studies (Corbetta, Miezin, Shulman, \& Petersen, 1993; Corbetta, Shulman, Miezin, Petersen, 1995), together with the analysis of attentional deficits in patients with unilateral visual neglect (Husain, Shapiro, Martin \& Kennard, 1997), suggest dominance of the right hemisphere as a substrate of visual attention. This idea was further supported by fMRI studies (Wojciulik \& Kanwisher, 1999). On the other hand, bilateral attentional advantage with no pronounced asymmetry was found for multiple object tracking (Alvarez \& Cavanagh, 2005), crowding (Chakravarthi \& Cavanagh, 2009), and elementary visual tasks (Reardon, Kelly, \& Matthews, 2009).

At the same time, bilateral attentional advantage was not found for visual search in healthy subjects (Luck, Hillyard, Mangun, \& Gazzaniga, 1989). A recent study by Alvarez, Gill, and Cavanagh (2012) showed hemifield independence in a visual search task for location-based selection but not for feature-based selection. Recent event-related potential (ERP) data on multiple object tracking demonstrate that when the target moves from one hemifield to the other, one hemisphere "loses" and the other hemisphere "catches up" its representation (Drew, Mance, Horowitz, Wolfe, \& Vogel, 2014). The process is sensitive to the observers' expectations about the trajectory of the target and thus is not controlled at the level of separate hemispheres.

When attention is directed to lexical stimuli, we might expect an interaction of lexical and attentional asymmetries. In general, verbal stimuli are identified more easily when presented in the right visual hemifield (RVF, i.e., the left hemisphere) and nonverbal stimuli - when presented in the left visual hemifield (LVF, i.e., the right hemisphere, e.g., Levine \& Koch-Weser, 1982). Such RVF advantage was found for word naming (Scott \& Hellige, 1998), word recognition under random spatial frequency sampling (Tadros, Dupuis-Roy, Fiset, Arguin, \& Gosselin, 2013), and other visual-verbal tasks.
Lexical decision experiments usually show word length effects for words presented in the LVF but not the RVF, which suggests holistic processing of the latter. Recognition is affected more by word length for words in the LVF than in the RVF (e.g., Ellis, Young, \& Anderson, 1988; Whitney \& Lavidor, 2004). In contrast, Jordan, Patching, and Milner (2000) found identical serial position effects for both visual fields in the Reicher-Wheeler task, in which participants had to identify a letter embedded either in a backward-masked word or in a random letter string using a 2-AFC procedure (Reicher, 1969; Wheeler, 1970). In a study by Lavidor and Bailey (2005), serial position and word length effects were compared in two different tasks-lexical decision and visual search. For visual search, performance in both hemifields showed similar effects of serial position. In lexical decision, response times to RVF words were not affected by letter amount. However, it had a significant effect on LVF performance. These results indicate that the effects of serial position and letter amount in the two visual fields are modulated by the task. Whereas letter-level processing (visual search and the Reicher-Wheeler tasks) may be similar in both hemifields, wholeword processing (lexical decision task) reveals qualitative differences between the hemifields.

A number of other studies has demonstrated that visual attention interacts with word processing and, in particular, with the word superiority effect across various perceptual and attentional paradigms, such as lateral masking (Fine, 2001), metacontrast masking (Luiga, Bachmann, \& Põder, 2002), the attentional blink (Falikman, 2002; Gorbunova \& Falikman, 2010), simultaneity judgements (Pechenkova \& Sinitsyna, 2009), and spatial cueing (Gorbunova \& Falikman, 2012). Using the central cueing paradigm, we (Gorbunova \& Falikman, 2012) presented words, pseudowords, and nonwords left or right to fixation and asked participants to shift attention to the letter string following the central cue, which was correct in $75 \%$ of trials. The observers were instructed to identify a letter in a letter string using a 2-AFC paradigm (Reicher, 1969; Wheeler, 1970). This study did not reveal any differences in processing between left and right hemifields, although there were differences between word and nonword processing for the effects of valid and invalid cues. Whereas valid cues led to both word and pseudoword superiority, thus emphasizing the role of orthographic regularity in the word superiority effect, invalid cues provided for word superiority only, revealing the role of word familiarity under inattention.

The word superiority effect has previously been observed for letter search in word strings (Krueger, Keen, \& Rublevich, 1974; Johnson \& Carnot, 1990). However, in earlier studies, we failed to find a pronounced word superiority effect for letter search in words and nonwords among other words or nonwords distributed over the display (Pantyushkov, Horowitz \& Falikman, 2008). What we did observe was a somewhat faster search within a word, a finding supporting earlier results by Johnson and Carnot (1990), and a faster word rejection as a distractor string not containing a target letter.

Thus, there is no unambiguous answer whether, and under which conditions, the visual search for an embedded letter might be efficient, that is, independent of the letter amount and the target letter posi- 
tion. Also, evidence is still controversial in the data about RVF/LVF asymmetry in letter search in various types of letter strings (words and nonwords). Therefore, in the present study, we carried out three experiments manipulating lexicality, target string location, and involvement of the two hemispheres. To find out whether the search was conducted letter-by-letter or whether simultaneous access to all letters within the word was possible under certain conditions, we presented a target letter either on the 2 nd or on the 5 th position within a six-letter word.

In Experiment 1, we studied the visual search for a letter within two letter strings (either words or nonwords) presented simultaneously on the computer screen. Our hypothesis was that we would observe differences in the search between words in the LVF and RVF. We also expected to find a general left-to-right bias (faster search within LVF as compared to RVF) determined by reading direction typical for most European languages, including Slavic ones.

In Experiment 2, to test the hypothesis that the involvement of one or both visual hemifields might influence the search mode, we presented one rather than two letter strings on the screen. We expected that the presence of just one letter string in the entire visual field might lead to its focal attentional processing without the contributions of hemispheric asymmetry.

Finally, in Experiment 3, we tested the possible contribution of lexicality priming (readiness to process a certain type of string) to the participants' choice of the search mode. In this experiment, we used different types of letter strings in each trial instead of using either two words or two nonwords, as in Experiment 1.

In all experiments, we prompted and expected our participants to maintain central fixation. We also kept the eccentricity of the target letter relative to fixation constant. However, our experimental setup did not allow for ruling out eye movements. In the General Discussion section, we will address this issue separately.

\section{EXPERIMENT 1}

In Experiment 1, we investigated the visual search for letters within words and nonwords in the right and left visual hemifields. In each trial, two letter strings were presented-one in the RVF and one in the LVF. The participants were instructed to search for a single letter, prespecified at the beginning of each trial, while maintaining central fixation. We hypothesized that the search for letters in words will be more efficient compared to nonwords. We also expected a left-right visual hemifield asymmetry in this task, with left hemifield benefit.

\section{Method}

\section{PARTICIPANTS}

Twenty-seven right-handed volunteers, students and graduates of Lomonosov Moscow State University and other universities in Moscow, participated in the study. Results of five participants were excluded due to extremely slow RTs (more than $M+1 S D$ ). The final data set included results from 22 participants, 3 males and 19 females.
All of them were native Russian speakers with normal or correctedto-normal vision. Their age varied between 17 and 28 years $(M=$ 20.1). All participants were naive to the experimental hypotheses.

\section{STIMULI}

The target was either the 2 nd or the 5 th letter in a string of six Cyrillic letters. The string could be a word or a nonword. The words were six-letter nouns from the Frequency Dictionary of Russian language ${ }^{1}$, balanced across frequency. Nonwords were constructed from these words by letter transposition and could not be recognized as words. Two hundred and eighty-eight words and 288 nonwords were used. Each word or nonword was presented twice-once containing and once not containing a target letter. Pairs of each word and nonword did not repeat. All words and nonwords were presented in black against a gray background. All letters were presented in upper case. The target letter was presented $7.3^{\circ}$ to the right or to the left from fixation (regardless whether it was the second or the fifth letter in the string). The nontarget letter strings were positioned symmetrically to target strings. In nontarget trials, either the second or fifth letter was positioned at $7.3^{\circ}$ from fixation (with equal probabilities) in order to counterbalance eccentricity. The string size was $3^{\circ}$ of visual angle horizontally and $0.8^{\circ}$ vertically.

\section{PROCEDURE}

The experiment was performed using the TX 4.01 tachistoscope software (Turkovsky, Bespalov, Vartanov, \& Kiselnikov, 2014). A PC with a Mitsubishi CRT monitor and a NVidia GeForce $4 \mathrm{mx}$ video card was used, at a refresh rate of $120 \mathrm{~Hz}$. A special console for recording RT data from the LPT port was used. Participants were sitting in a dark room, with a chin rest maintaining a viewing distance of $70 \mathrm{~cm}$. The experiment consisted of 576 trials, divided into four parts with short breaks between them. In 192 trials, the target was not present (catch trials, not further analyzed in data analysis), the other 384 trials were distributed between the different conditions, with 48 trials for each combination of the three independent variables (visual hemifield, letter string type, target letter position). The order of presentation was randomized.

Participants were tested individually. Each trial began with a $2 \mathrm{~s}$ target letter presentation at the center of the screen. The target letter was set separately for each trial. Afterwards, a fixation cross was presented for $1 \mathrm{~s}$ in the center of the screen, and participants were instructed to focus on it. The fixation display was followed by a presentation of two letter strings to the left and to the right from the center of the screen. These two letter strings were of the same type (both were either words or nonwords). Any one of the strings could contain the target letter. The participants' task was to find the target as fast as possible and to press a specified key on the console. In case the target letter was not present the participant had to press another key. Both keys were pressed with the right hand. Letter strings remained on the screen until response. The trial design is shown in Figure 1. A training session of 10 trials preceded the experiment. 


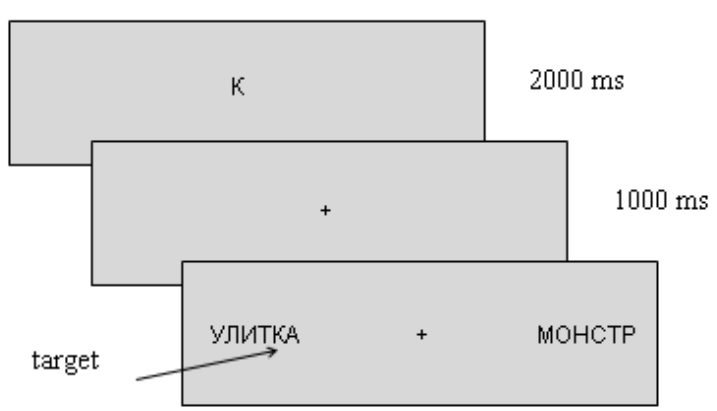

FIGURE 1.

Trial design in Experiment 1 (target-present, word trial). УЛИТКА is a Russian word that means "snail", MOHCTP is a Russian word that means "monster".

\section{Results}

Reaction times and accuracy were compared between the different conditions. Reaction times longer than three $S D$ s above the mean were excluded from the analysis (73 from 8448 overall trials). There were no RTs shorter than three SDs below the mean. Trials with incorrect responses were also excluded from the RT analysis. The percentage of excluded data was thus $7.45 \%$. Data analysis was performed using SPSS 17.0. The multivariate repeated-measures analysis of variance (rmANOVA) was used. The factors were the visual hemifield (left or right), the letter string type (word or nonword), and the target position (second or fifth letter in the string). Pairwise comparisons (Bonferroni

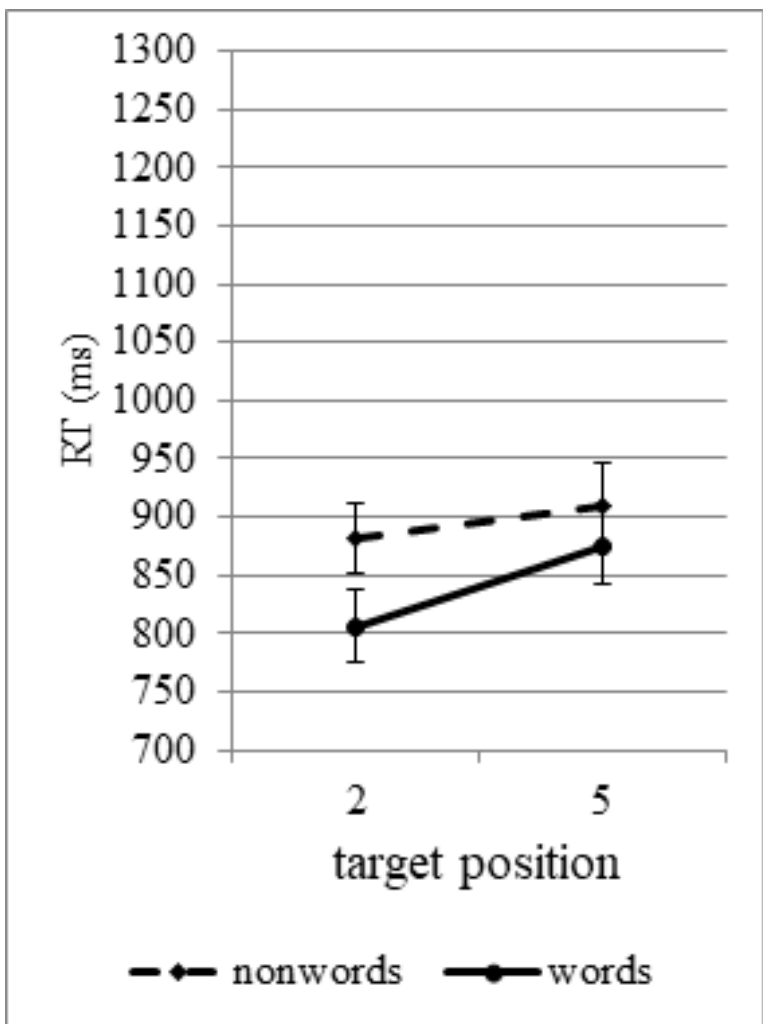

corrected) for different target positions for each type of letter strings and each hemifield were also performed separately. For target-absent trials, paired-samples $t$-tests were conducted to compare the RTs for words and nonwords.

\section{REACTION TIMES}

The mean RTs from target-present trials are presented in Figure 2. Responses were faster for left than for right strings, $F(1,21)=21.94$, $p=.001, \eta_{\mathrm{p}}{ }^{2}=0.511$, for words than for nonwords, $F(1,21)=54.64$, $p=.001, \eta_{\mathrm{p}}{ }^{2}=0.722$, and for targets at the $2 \mathrm{nd}$ than at the 5 th position, $F(1,21)=24.83, p=.001, \eta \mathrm{p}^{2}=0.542$. There were no two-way interactions, $F(1,21) \leq 2.1, p \geq .160$, but the three-way interaction was significant, $F(1,21)=12.71, p=.002, \eta_{\mathrm{p}}{ }^{2}=0.377$.

As the data pattern in Figure 2 suggests, this interaction reflected diverging two-way interactions of Target Position $\times$ Lexicality when the ANOVA was conducted separately for the two visual fields: $F(1,21)$ $=3.14, p=.091, \eta_{\mathrm{p}}{ }^{2}=0.130$, and $F(1,21)=12.40, p=.002, \eta_{\mathrm{p}}{ }^{2}=0.371$ for the LVF and the RVF, respectively. In the LVF, responses were the fastest when the letter was at the 2 nd position in a word, $t(21) \geq 4.28$, $p \leq 0.002$, while the other three conditions (2nd position in nonwords, 5th position in words, 5th position in nonwords) did not differ from each other, $t(21) \leq .52, p \geq 0.120$. In contrast, in the RVF, responses were the slowest when the letter was at the 5th position in a nonword, $t(21) \geq 4.63, p<0.001$, while the other three conditions (2nd position in words, 5th position in words, 2nd position in nonwords) did not differ from each other, $t(21) \leq 2.28, p \geq 0.199$.

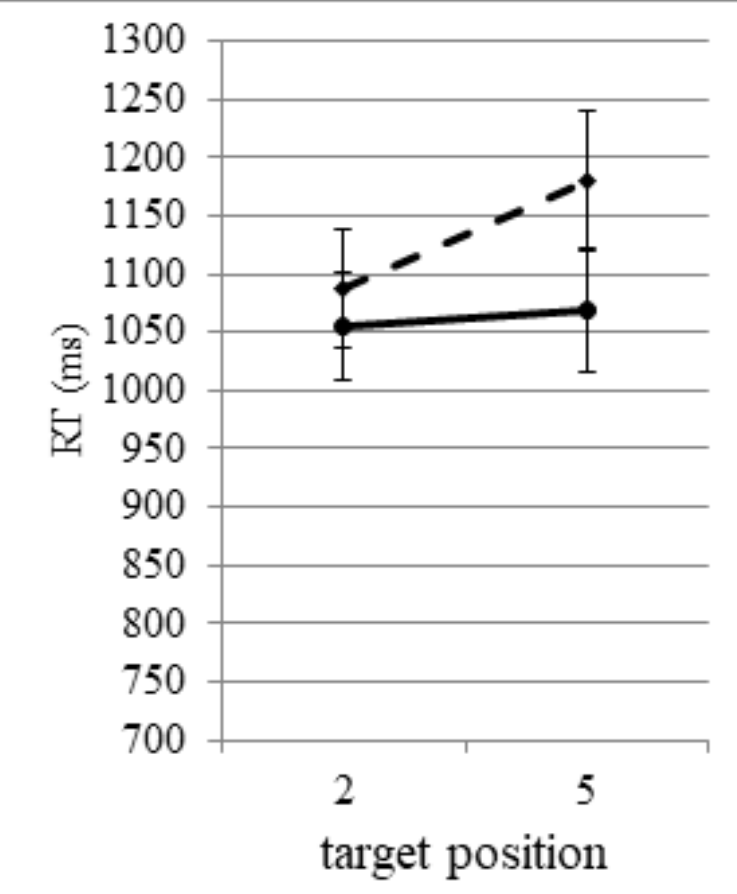

- nonwords $\longrightarrow$ words

\section{FIGURE 2.}

Reaction time data for Experiment 1 for the left visual field (left panel) and for the right visual field (right panel). Error bars indicate the SEM. 


\begin{tabular}{llcccc}
\hline TABLE 1. & \multicolumn{3}{c}{} \\
Reaction Times as a Function of Letter Position, Visual Field, \\
and Lexicality in Experiments 1-3 & \multicolumn{2}{c}{ LVF } & \multicolumn{2}{c}{ RVF } \\
\cline { 3 - 6 } & & 2nd & 5 th & 2nd & 5th \\
& & letter & letter & letter & letter \\
\hline \multirow{4}{*}{ Experiment 1 } & \multirow{2}{*}{ words } & 807 & 876 & 1055 & 1069 \\
& & \pm 149 & \pm 159 & \pm 221 & \pm 252 \\
& nonwords & 882 & 910 & 1087 & 1179 \\
& & \pm 145 & \pm 165 & \pm 242 & \pm 280 \\
Experiment2 & words & 789 & 829 & 772 & 865 \\
& & \pm 159 & \pm 174 & \pm 153 & \pm 170 \\
& nonwords & 850 & 903 & 800 & 925 \\
& \multirow{2}{*}{ words } & \pm 167 & \pm 208 & \pm 182 & \pm 188 \\
Experiment3 & & \pm 152 & 853 & 1069 & 1144 \\
& \multirow{2}{*}{ nonwords } & 875 & 891 & 1081 & 1187 \\
& & \pm 157 & \pm 162 & \pm 206 & \pm 255 \\
\hline
\end{tabular}

Note. The values are given in a $M \pm S D$ format. $L V F=$ left visual field; $\mathrm{RVF}=$ right visual field.

The paired samples $t$-test for target-absent trials revealed slower RTs for nonwords, $(M=1310 ; S D=259)$ as compared to words ( $M$ $=1236 ; S D=228), t(21) \geq 5.78, p<0.001$. Mean and $S D$ values are presented in Table 1.

\section{ACCURACY}

The accuracy data are presented in Figure 3. Responses were more accurate for the LVF as compared to the RVF, $F(1,21)=4.81, p=.040$, $\eta_{\mathrm{p}}{ }^{2}=0.186$, and for words as compared to nonwords, $F(1,21)=6.92$, $p=.016, \eta_{\mathrm{p}}{ }^{2}=0.248$. Accuracy did not differ between the 2 nd and 5 th target positions, $F(1,21)=0.53, p=.477, \eta_{\mathrm{p}}{ }^{2}=0.024$. The interaction between visual hemifield and target position was significant, $F(1,21)=9.18, p=.006, \eta_{\mathrm{p}}^{2}=0.304$. The other two interactions were not significant, $F(1,21) \leq 0.02, p \geq .884$. The three-way interaction was significant, $F(1,21)=8.33, p=.009, \eta_{\mathrm{p}}{ }^{2}=0.284$.

Two-way ANOVAs of Target Position $\times$ Lexicality were conducted separately for the two visual fields. For both visual fields, accuracy was better for words as compared to nonwords, $F(1,21)=4.68, p=.042$, $\eta_{\mathrm{p}}{ }^{2}=0.182$, and $F(1,21)=4.48, p=.046, \eta_{\mathrm{p}}{ }^{2}=0.178$, for the LVF and the RVF, respectively. No significant effects of target position or interactions were revealed for the LVF and the RVF analyzed separately, $F(1,21) \leq 3.23, p \geq .087$.

Also, two-way ANOVAs of Target Position $\times$ Hemifield were conducted separately for words and nonwords. For nonwords, a significant Target Position $\times$ Hemifield interaction was observed, $F(1,21)=17.42$, $p<.001, \eta_{\mathrm{p}}^{2}=0.453$, whereas for words, no interaction was revealed, $F(1,21)=0.11, p=.743$. Mean and $S D$ values are presented in Table 2 . benefit.

\section{Discussion}

The experiment revealed shorter RTs and better accuracy for words compared to nonwords, thus providing support for the word superiority effect. This result is inconsistent with the results of an earlier study by Pantyushkov et al. (2008) who did not observe a word superiority

\begin{tabular}{|c|c|c|c|c|c|}
\hline \multicolumn{6}{|c|}{$\begin{array}{l}\text { TABLE } 2 . \\
\text { Accuracy as a Function of Letter } \\
\text { Lexicality in Experiments in 1-3 }\end{array}$} \\
\hline & & \multicolumn{2}{|c|}{ LVF } & \multicolumn{2}{|c|}{ RVF } \\
\hline & & $\begin{array}{l}\text { 2nd } \\
\text { letter }\end{array}$ & $\begin{array}{c}5 \text { th } \\
\text { letter }\end{array}$ & $\begin{array}{l}\text { 2nd } \\
\text { letter }\end{array}$ & $\begin{array}{c}5 \text { th } \\
\text { letter }\end{array}$ \\
\hline \multirow{4}{*}{ Experiment 1} & \multirow{2}{*}{ words } & 95.6 & 95.4 & 94.3 & 93.7 \\
\hline & & \pm 4.6 & \pm 4.7 & \pm 5.7 & \pm 4.9 \\
\hline & \multirow{2}{*}{ nonwords } & 93.5 & 95.1 & 94.1 & 91.4 \\
\hline & & \pm 6.6 & \pm 3.7 & \pm 6.4 & \pm 6.3 \\
\hline \multirow{4}{*}{ Experiment 2} & \multirow{2}{*}{ words } & 95.6 & 94.3 & 97.4 & 95 \\
\hline & & \pm 4 & \pm 3.6 & \pm 2.5 & \pm 4.9 \\
\hline & \multirow{2}{*}{ nonwords } & 93.4 & 94.8 & 96.6 & 94.3 \\
\hline & & \pm 4.7 & \pm 4.2 & \pm 3.9 & \pm 3.8 \\
\hline \multirow{4}{*}{ Experiment 3} & \multirow{2}{*}{ words } & 96.3 & 96.4 & 96 & 94.7 \\
\hline & & \pm 5.3 & \pm 7.5 & \pm 3.8 & \pm 5.7 \\
\hline & \multirow{2}{*}{ nonwords } & 95.5 & 95.1 & 94.6 & 92.8 \\
\hline & & \pm 6 & \pm 6.5 & \pm 5.9 & \pm 6.7 \\
\hline
\end{tabular}

Note. The values are given in a $M \pm S D$ format. $L V F=$ left visual field; $\mathrm{RVF}=$ right visual field.

effect in visual search. This result can be attributed to the differences in the number and arrangement of stimuli used in that study: In each trial, several $(3,7$, or 10$)$ letter strings were presented at random locations on the display. In our current study, only two letter strings were presented at predictable locations. A recent study by Starrfelt, Petersen, and Vangkilde (2013) also did not reveal any word superiority when multiple stimuli were presented simultaneously. Thus, the absence of the word superiority effect in the study by Pantyushkov et al. (2008) could be related to the reduction of visual working memory capacity for complex objects. The RT analysis of target-absent trials revealed the same pattern in the present study as in Pantyushkov et al. (2008): The RTs for words were faster than for nonwords, suggesting that it is easier to reject a word that does not contain a target letter as compared to a nonword.

The mean RT for stimuli in the LVF was shorter than for the RVF. Accuracy was also higher for the LVF as compared to the RVF. This result might be related to the left-to-right reading habit, due to which subjects started searching in the LVF and then proceeded to the RVF. The significant effect of target position for words in the LVF and for nonwords in the RVF suggests a letter-by-letter search. In contrast, no significant effect of target position for nonwords in the LVF and for words in the RVF indicates that the participants got access to all letters within the string at once. These results might reveal differences between novel and familiar stimulus processing. For novel stimuli (nonwords), hemispheric information processing strategies (Bever, 1975) play the most important role. As holistic information processing is characteristic of the right hemisphere, the search within nonwords presented in the LVF takes advantage from the simultaneous access to all letters of the letter string. On the other hand, successive informational processing, characteristic of the left hemisphere, leads to the letter-by-letter visual search within nonwords in the RVF. In contrast, for familiar stimuli (words), top-down influences based on the observer's experience and expectations are more important than 


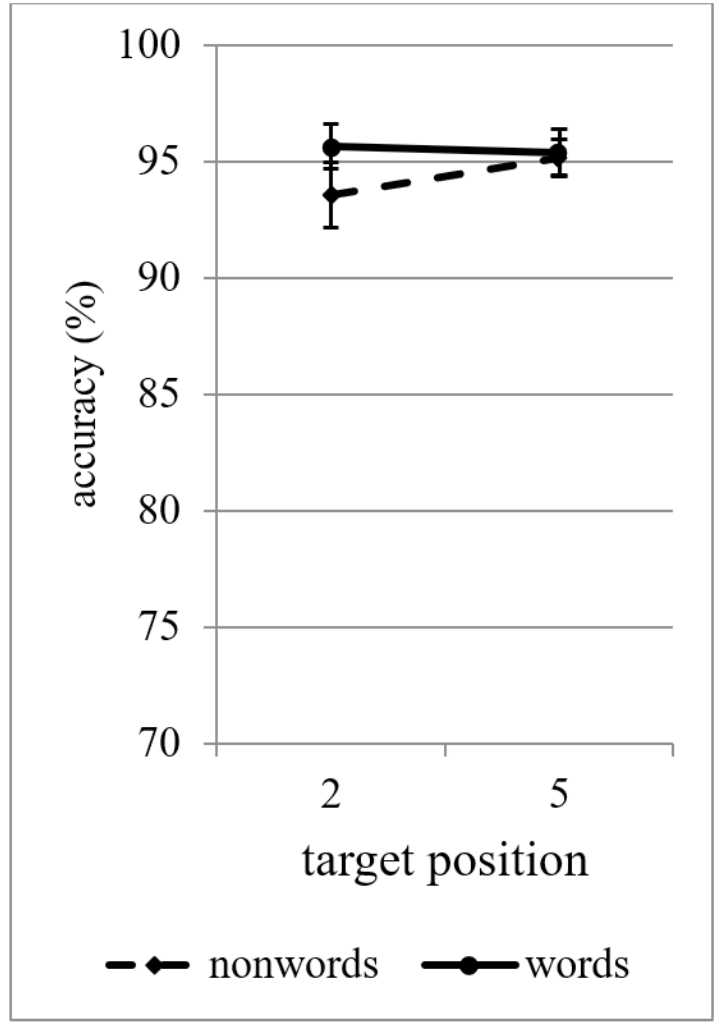

FIGURE 3.

Accuracy data for Experiment 1. Error bars indicate the SEM

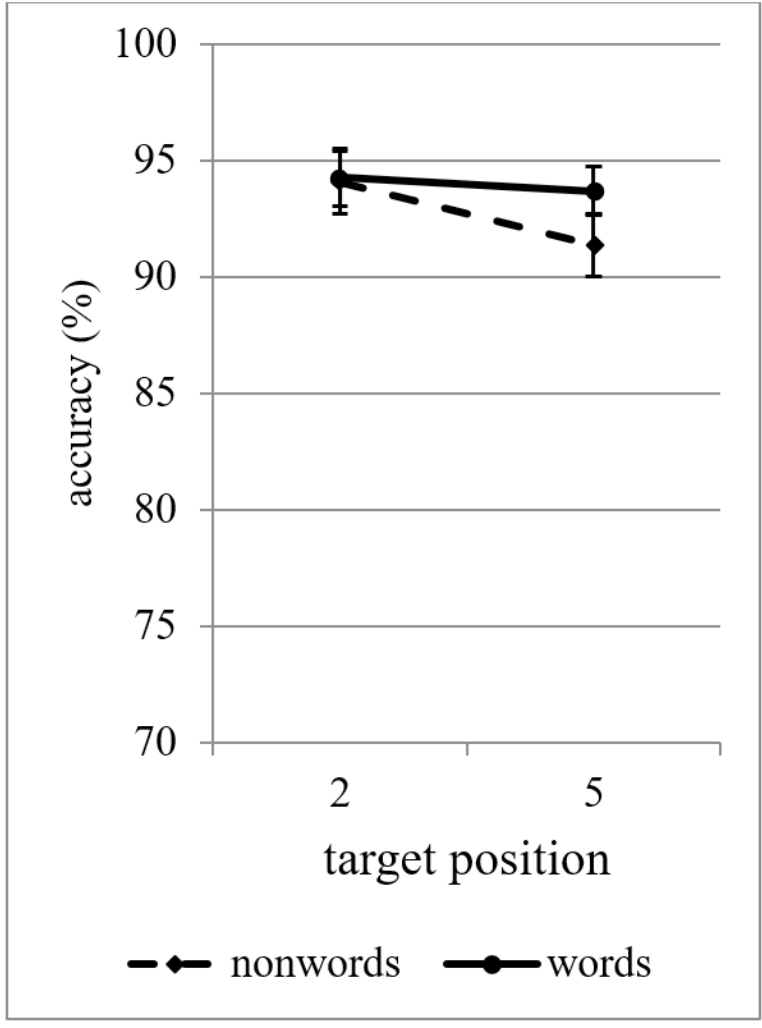

ter strings in both hemifields, as well as a faster search in the RVF as compared to Experiment 1. Alternatively, a faster search within letter strings in the RVF as compared to the LVF might be expected, due to the hemispheric asymmetry in lexical information processing.

\section{Method}

ability of all letters within words presented in the RVF, with no target letter position effect.

Our results are inconsistent with the results of Lavidor and Bailey (2005), who found positional effects for words in the RVF in the visual search task. However, this discrepancy in results might be attributed to the number of stimuli presented in the visual field. In the Lavidor and Bailey experiment, only one letter string was presented in one of the hemifields in each trial, whereas in our study, two letter strings were presented, one in each hemifield. Another possibility is that the observed search mode within words in the RVF is partly due to the participants' readiness to process a particular type of stimulus. It might be that the letter string in the LVF primes processing of the letter string in the RVF

\section{EXPERIMENT 2}

The second experiment tested the contribution of letter strings in both visual hemifields to the strategy of visual search for letters within words and nonwords. In each trial, only one letter string was presented, either in the RVF or the LVF. Basing on previous results by Lavidor and Bailey (2005), we expected a letter-by-letter search within both types of let-

\section{PARTICIPANTS}

Twenty right handed students and graduates of Lomonosov Moscow State University and other universities in Moscow participated in the study. None of them participated in Experiment 1. Results of one participant were excluded from further analysis due to slow RTs (higher than one $S D$ above the mean). The final data set included data from 19 participants, 8 males and 11 females. The age varied between 17 and 35 years $(M=21.3)$. All participants were native Russian speakers and had normal or corrected-to-normal vision. All were naive to the experimental hypotheses.

\section{STIMULI}

The stimuli were the same as in Experiment 1, except that within each trial, only one letter string was presented, either in the LVF or in the RVF.

\section{PROCEDURE}

The procedure was the same as in Experiment 1. The trial design is shown in Figure 4. 


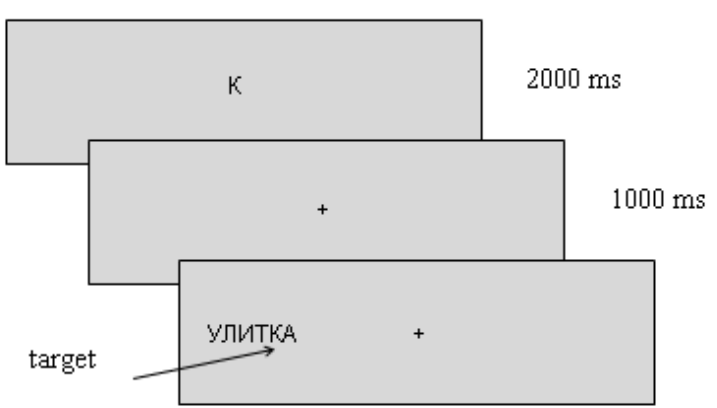

FIGURE 4.

Trial design in Experiment 2 (target-present, word trial).

\section{Results}

Data analysis was analogous to Experiment 1. Reaction times longer than three SDs above the mean were excluded from the analysis (111 from 8448 overall trials). There were no RTs shorter than three SDs below the mean. Trials with incorrect responses were excluded from the RT analysis. The percentage of excluded data was $7.57 \%$.

\section{REACTION TIMES}

The mean RTs from target-present trials are presented in Figure 5. Responses were faster for the 2nd letter than for the 5 th, $F(1,18)=$ $39.03, p<.001, \eta_{\mathrm{p}}{ }^{2}=0.684$, and for words than for nonwords, $F(1,18)=$ $44.33, p<.001, \eta_{\mathrm{p}}{ }^{2}=0.711$. There was no main effect of visual field, $F(1$,

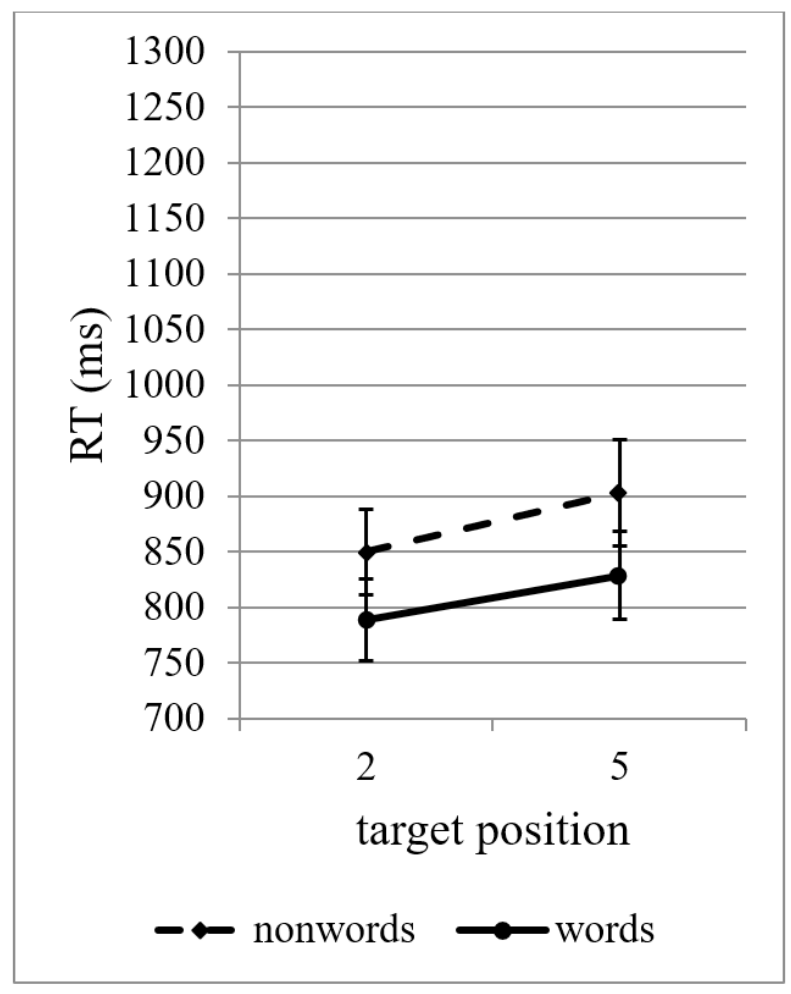

\section{FIGURE 5.}

Reaction Time data for Experiment 2 for the left visual field (left panel) and the right visual field (right panel). Error bars indicate the SEM.
18) $=0.06, p=.813, \eta_{\mathrm{p}}^{2}=0.003$, but visual field interacted with target position, $F(1,18)=14.76, p<.001, \eta_{\mathrm{p}}{ }^{2}=0.451$, as did string lexicality, $F(1,18)=5.64, p=.029, \eta p^{2}=0.238$. The interaction between visual field and lexicality was not significant, $F(1,18)=3.03, p=.099, \eta_{\mathrm{p}}{ }^{2}$ $=0.144$. The three-way interaction was also nonsignificant, $F(1,18)=$ $0.78, p=.389, \eta_{\mathrm{p}}{ }^{2}=0.042$. The target position effect (faster responses for the 2nd than the 5th position) was larger in the RVF, $F(1,18)=$ $54.96, p<.001, \eta_{\mathrm{p}}{ }^{2}=0.753$, than in the LVF, $F(1,18)=9.49, p=.006$, $\eta_{\mathrm{p}}{ }^{2}=0.345$. Separate ANOVAs for either target position revealed that for targets in the 2nd position, the RT was shorter in the RVF compared to the LVF, $F(1,18)=9.82, p=.006, \eta_{\mathrm{p}}{ }^{2}=0.353$, whereas for targets in the 5th position, the RT was higher in the RVF compared to the LVF, $F(1,18)=6.07, p=.024, \eta_{\mathrm{p}}{ }^{2}=0.252$.

In order to explain the Target Position $\times$ Lexicality interaction, the effects of position were calculated separately for words and nonwords. The position effect was larger for nonwords, $F(1,18)=35.71$, $p<.001, \eta_{\mathrm{p}}{ }^{2}=0.665$, as compared to words, $F(1,18)=33.31, p<.001$, $\eta_{\mathrm{p}}^{2}=0.649$.

The paired-samples $t$-test for target-absent trials revealed slower RTs for nonwords $(M=1085 ; S D=316)$ as compared to words $(M=1012 ; S D=254), t(18) \geq 3.71, p \leq .002$. Mean and $S D$ values are presented in Table 1.

\section{ACCURACY}

The accuracy data are presented in Figure 6. Responses were more accurate for the RVF than for the $\operatorname{LVF}, F(1,18)=7.32, p=.014$, $\eta_{\mathrm{p}}{ }^{2}=0.289$. There were no differences between words and nonwords,

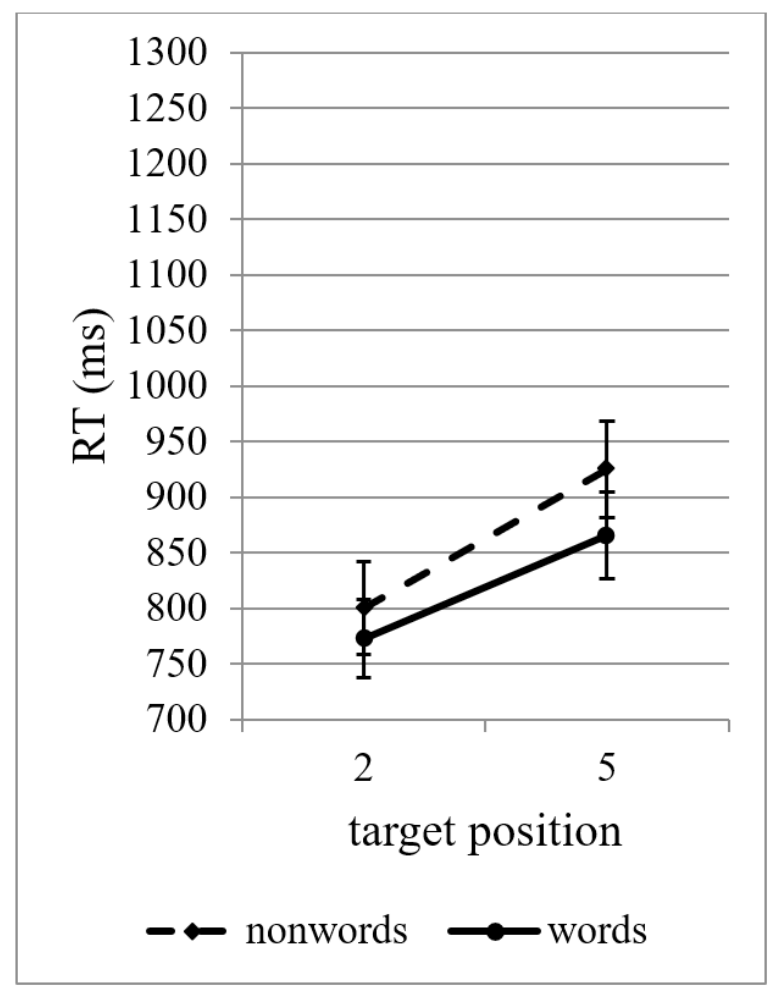




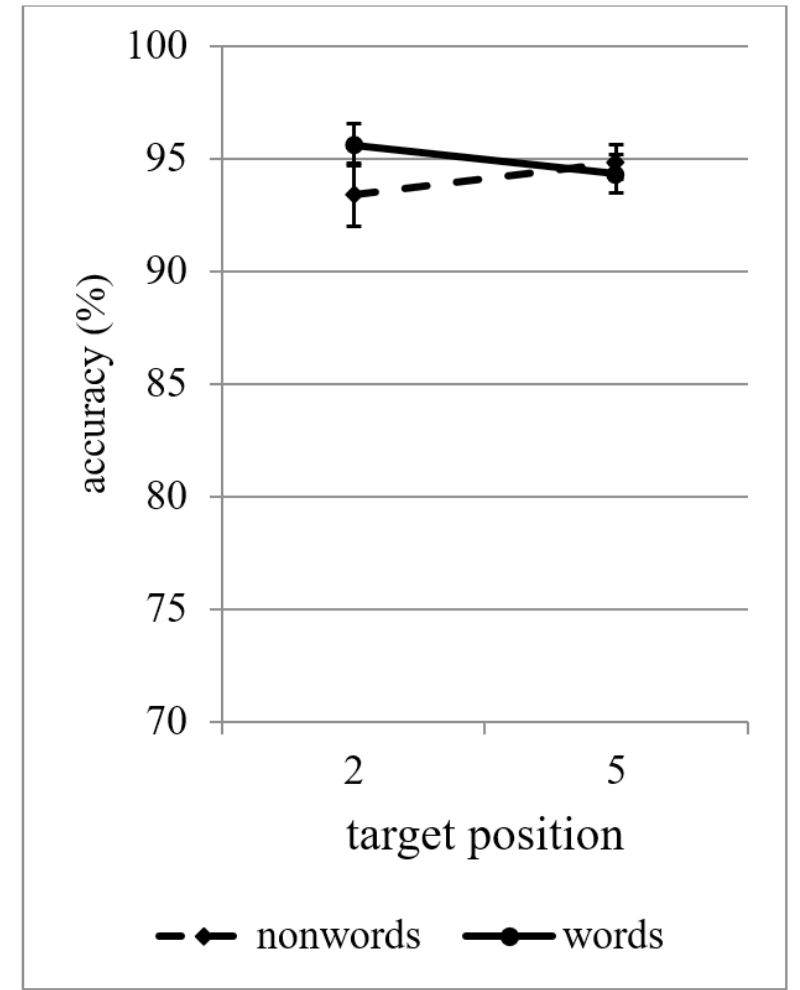

FIGURE 6.

Accuracy data for Experiment 2. Error bars indicate the SEM.

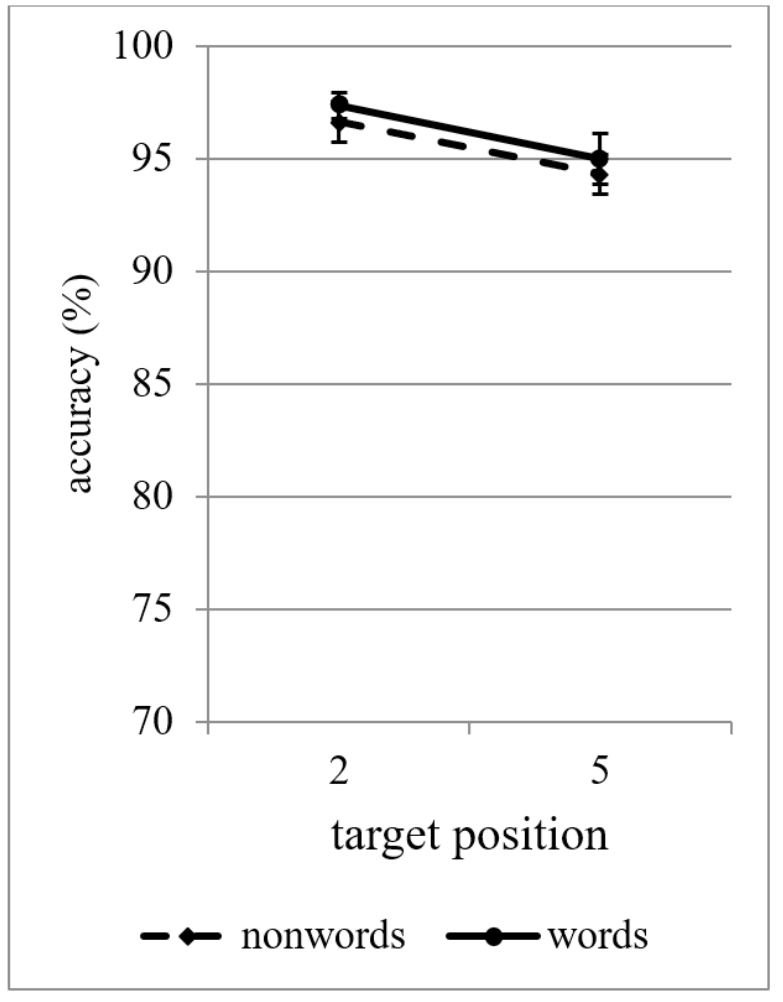

type. This result is inconsistent with the data obtained in many previous experiments (Ellis et al., 1988; Madrid, Lavie, \& Lavidor, 2010), where shorter RTs were found for lexical stimuli in the RVF as compared to the LVF. However, opposite visual field effects for targets on the 2nd and 5th position were revealed: For targets on the 2nd position, the RT was lower in the RVF compared to the LVF, whereas for targets on the 5th position, the opposite pattern was observed. Thereby, the differences in search slopes in the LVF and the RVF might at least partly reflect shorter RTs for the 2nd position targets in the RVF.

Accuracy was higher in the RVF than the LVF (regardless of string type), which might be related to the specialization of the left hemisphere for processing verbal information.

Significant differences revealed by pairwise comparisons between different target positions for each combination of string type and visual field suggest a letter-by-letter search in all four conditions: within words in the LVF, within nonwords in the LVF, within words in the RVF, and within nonwords in the RVF. These position effects are consistent with the results of Lavidor and Bailey (2005) and support our hypothesis about the differences between their study and our Experiment 1. We suggest that the use of different search strategies depends of the number of stimuli in the visual field and the involvement of one versus both visual hemifields. The processing of the letter string as a whole with simultaneous access to all letters might result from an overload of the visual system. When just one letter string is presented in either the LVF or the RVF (Experiment 2), letter-by-letter search is a reasonable default option, but when there is a letter string in each hemifield at the 
same time (Experiment 1), it might be more rational to choose a search mode depending on the string type and the hemispheric specialization. Still, the question remains whether the benefit from the holistic processing of words presented in the RVF in Experiment 1 was due to letter string lexicality itself or whether the visual system was to be primed for words to take advantage of the more efficient processing mode.

\section{EXPERIMENT 3}

In Experiment 3, we investigated the role of set for processing of a particular type of letter string in visual search for letters within words and nonwords in the RVF. In Experiment 1, we did not observe a target position effect for target letters within words in the RVF, which we believed to be due to top-down influences on word processing. In Experiment 3, we examined whether these influences could be at least partly related to the readiness to process a letter string of a particular type (a word in the participants' native language). When starting to search for a target letter within the first letter string in the LVF in Experiment 1, the participants might expect to find the same type of string in the RVF and prepare to use available processing mechanisms. We modified the procedure so that in each trial, two letter strings were presented-one in the RVF and one in the LVF, as in Experiment 1. However, unlike in Experiment 1, these strings were of different types (word and nonword).

\section{Method}

\section{PARTICIPANTS}

Twenty-seven right-handed students and graduates of Lomonosov Moscow State University and some other universities participated in the study. None of them participated in Experiment 2, one participated in Experiment 1 (the interval between the experiments was 13 months). Results of four participants were excluded due to high RTs (higher than one $S D$ above the mean). The final data set included results from 23 participants, 9 males and 14 females. Their age varied between 17 and 25 years $(M=20.3)$. All of them were naive to the experimental hypotheses, were native Russian speakers, and had normal or corrected-to-normal vision.

\section{STIMULI AND PROCEDURE}

The stimuli were the same as in Experiment 1, except that the two letter strings presented in each trial were of a different type (word and nonword simultaneously). The procedure was the same as in Experiment 1 . The trial design is shown in Figure 7.

\section{Results}

Data analysis was analogous to Experiment 1. Reaction times longer than three SDs above the mean were excluded from the analysis (103 from 8448 overall trials). Again, there were no RTs shorter than three $S D$ s below the mean. Trials with incorrect responses were also excluded. The percentage of excluded data was thus $7.26 \%$.

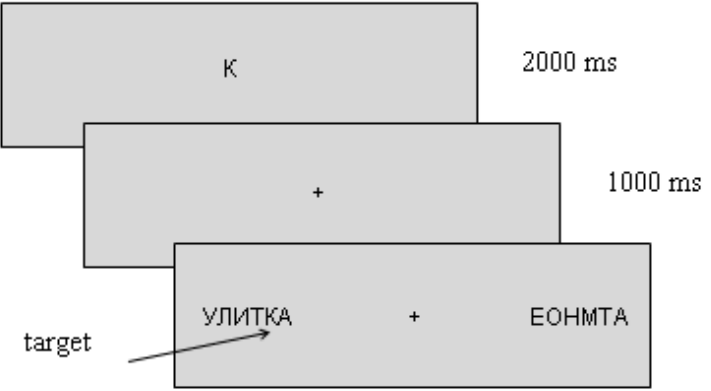

\section{FIGURE 7.}

Trial design in Experiment 3 (target-present, word trial). EOHMTA is a nonword.

\section{REACTION TIMES}

The mean RTs from target-present trials are presented in Figure 8. Responses were faster for left than for right strings, $F(1,22)=40.39$, $p<.001, \eta_{\mathrm{p}}{ }^{2}=0.647$, for words than for nonwords, $F(1,22)=44.89$, $p<.001, \eta_{\mathrm{p}}^{2}=0.671$, and for targets at the 2 nd than the 5 th position, $F(1,22)=61.78, p<.001, \eta_{p}{ }^{2}=0.737$. The interaction between visual field and target position was significant, $F(1,22)=10.00, p=.005$, $\eta_{\mathrm{p}}^{2}=0.313$. The three-way interaction was also significant, $F(1,22)=4.86, p=.038, \eta_{p}{ }^{2}=0.181$. Other two-way interactions were nonsignificant, $F(1,22) \leq 2.2, p \geq .160$.

In order to explain the Visual Field $\times$ Target Position interaction, two-way ANOVAs of Target Position $\times$ Letter string were conducted separately for the two visual fields. The target position effect was larger for the RVF, $F(1,22)=44.35, p<.001, \eta_{\mathrm{p}}{ }^{2}=0.668$, as compared to the LVF, $F(1,22)=14.11, p=.001, \eta_{\mathrm{p}}{ }^{2}=0.391$. The effect of visual field was larger for targets on the 5 th position, $F(1,22)=48.65, p<.001$, as compared to targets on the 2 nd position, $F(1,22)=30.24, p<.001, \eta_{\mathrm{p}}{ }^{2}$ $=0.579$.

In order to explain the three-way interaction, two-way ANOVAs for Visual Field $\times$ Letter String were conducted separately for the 2nd and the 5 th target position. For targets on the 2 nd position, responses were faster for words as compared to nonwords, $F(1,22)=24.05$, $p<.001, \eta_{\mathrm{p}}{ }^{2}=0.522$; and for the LVF as compared to the RVF, $F(1,22)$ $=30.24, p<.001, \eta_{p}{ }^{2}=0.579$. A significant Visual Field $\times$ Letter String interaction was revealed, $F(1,22)=11.73, p=.002, \eta_{p}{ }^{2}=0.348$. For the LVF, responses were faster for words as compared to nonwords, $F(1,22)$ $=28.49, p<.001, \eta_{\mathrm{p}}{ }^{2}=0.564$. For the RVF, no difference between words and nonwords was observed, $F(1,22)=1.20, p=.284$. For targets on the 5th position, responses were also faster (a) for words as compared to nonwords, $F(1,22)=19.66, p<.001, \eta p^{2}=0.472$, and (b) for the LVF as compared to the RVF, $F(1,22)=48.65, p<.001, \eta_{p}^{2}=0.689$. However, no Visual Field $\times$ Letter String interaction was revealed, $F(1,22)=0.05$, $p=.823$. Mean and $S D$ values are presented in Table 1.

\section{ACCURACY}

The accuracy data are presented in Figure 9. Responses were more accurate for words as compared to nonwords, $F(1,22)=8.62, p=.008$, 

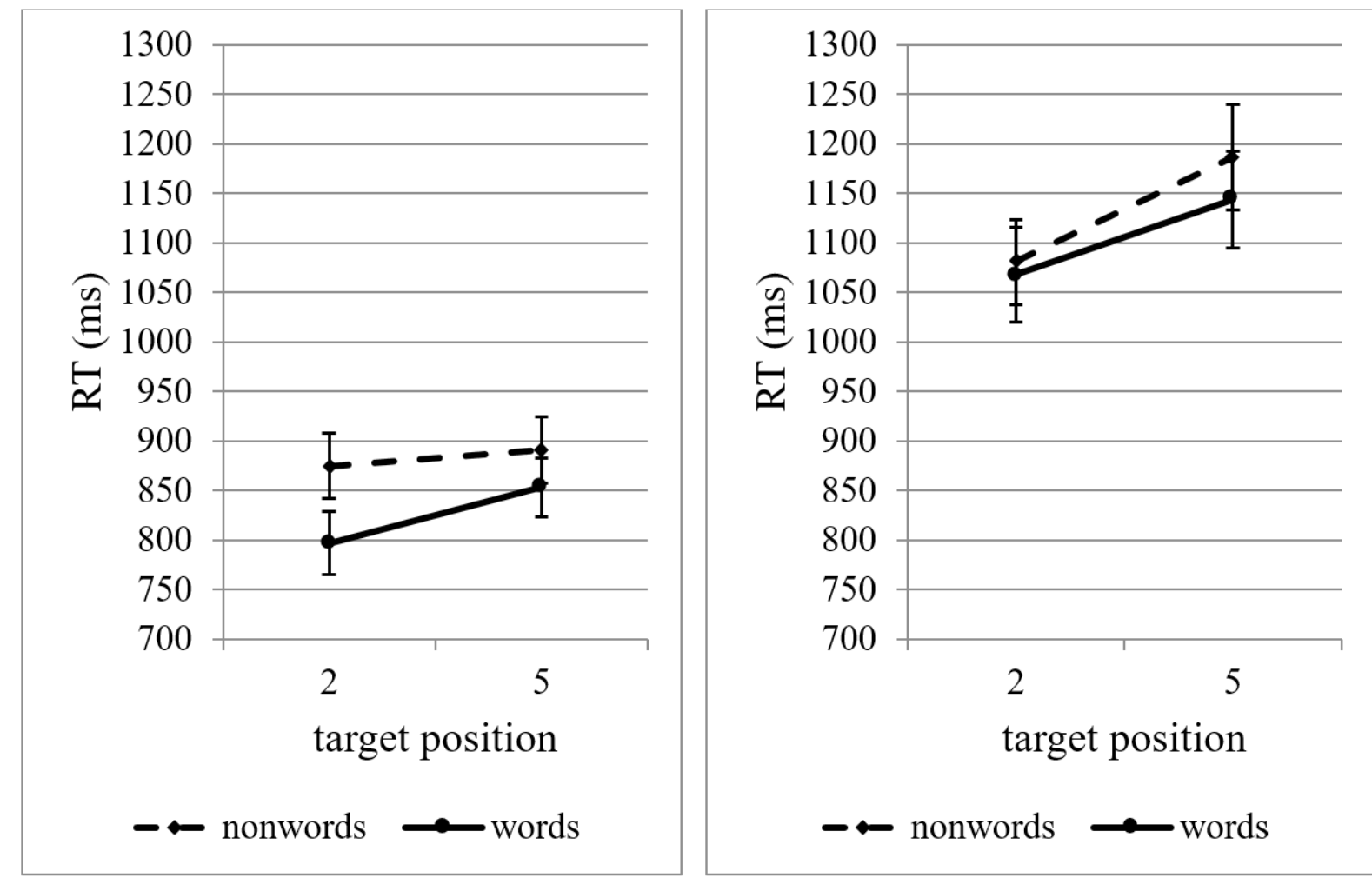

\section{FIGURE 8.}

Reaction time data for Experiment 3 for the left visual field (left panel) and the right visual field (right panel). Error bars indicate the SEM.
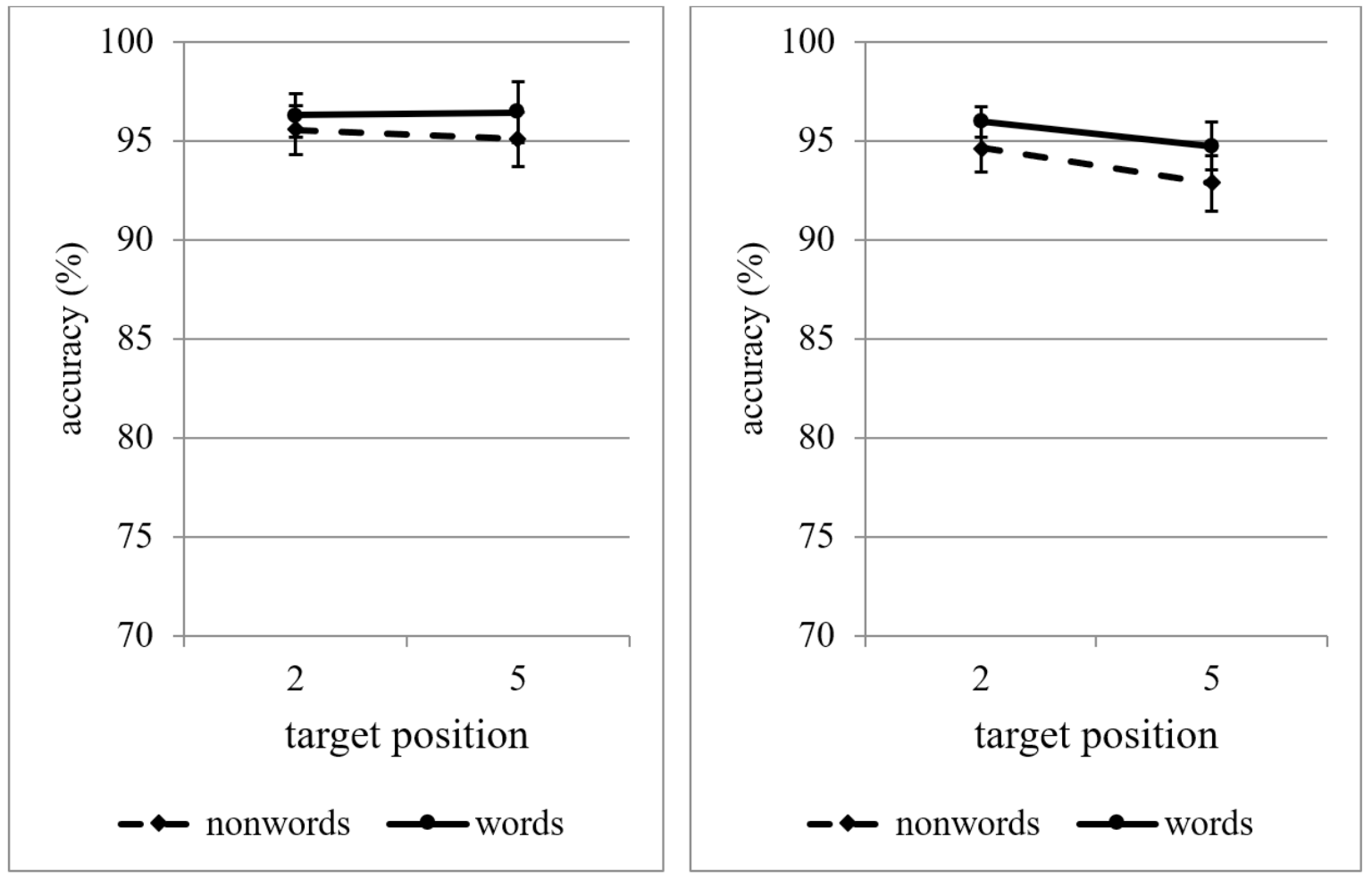

\section{| FIGURE 9.}

Accuracy data for Experiment 3 Error bars indicate the SEM. 
$\eta_{\mathrm{p}}{ }^{2}=.281$. All other effects were nonsignificant, $F(1,22) \leq 2.03, \mathrm{p} \geq$ .168. No two-way interactions were significant, $F(1,22) \leq 3.04, p \geq .095$. The three-way interaction was also nonsignificant, $F(1,22)=0.001$, $p=.982, \eta_{\mathrm{p}}{ }^{2}=.000$. Mean and $S D$ values are presented in Table 2 .

\section{Comparison of the Experiments}

An additional analysis was conducted in order to reveal any possible differences between the unilateral (Experiment 2) and the bilateral (Experiments 1 and 3) conditions. A mixed ANOVA was applied to compare the RT data of Experiment 2 with the pooled RT data of Experiments 1 and 3 (45 participants total). Only the effects of the Experiment factor are reported here. The experiments differed from each other in RT, $F(1,62)=10.08, p=.002, \eta_{\mathrm{p}}{ }^{2}=0.140$. An interaction between visual field and experiment was revealed, $F(1,62)=$ $25.49, p<.001, \eta_{\mathrm{p}}{ }^{2}=0.291$. All other interactions were nonsignificant. Consequently, the effect of experiment was calculated separately for either visual field. For the LVF, the effect of experiment was nonsignificant, $F(1,62)=0.19, p=.663$. For the RVF, responses were faster for the unilateral (Experiment 2) presentation, $F(1,62)=20.47, p<$ $.001, \eta_{\mathrm{p}}^{2}=0.248$.

Another question refers to any possible differences within bilateral stimulation between pairs of same type (Experiment 1) and pairs of different types (Experiment 3). A mixed ANOVA was applied to compare the RT data of Experiment 1 and Experiment 3. The experiments did not differ from each other in RT, $F(1,43)=0.01, p=.939$, $\eta_{\mathrm{p}}{ }^{2}<0.001$. A three-way interaction for Lexicality $\times$ Visual Field $\times$ Experiment was found, $F(1,43)=5.44, p=.024, \eta_{\mathrm{p}}{ }^{2}=0.112$. Another significant three-way interaction referred to Target Position $\times$ Visual Field $\times$ Experiment, $F(1,43)=5.71, p=.021, \eta_{\mathrm{p}}{ }^{2}=0.117$.

In order to understand the Lexicality $\times$ Visual Field $\times$ Experiment interaction, the effect of experiment was tested separately for the RVF and the LVF. For the RVF, unlike the LVF, a significant Lexicality $\times$ Experiment interaction was observed, $F(1,43)=10.73, p=.002, \eta_{\mathrm{p}}{ }^{2}$ $=0.200$. Consequently, effect of lexicality in the RVF was tested separately for Experiments 1 and 3. The effect of lexicality was larger in Experiment $1, F(1,21)=51.79, p<.001, \eta_{\mathrm{p}}{ }^{2}=0.712$, as compared to Experiment $3, F(1,22)=10.28, p=.004, \eta_{\mathrm{p}}^{2}=0.318$.

In order to understand the Target Position $\times$ Visual Field $\times$ Experiment interaction, separate ANOVAs were conducted for each experiment. For both experiments, responses were faster (a) for left than for right strings, $F(1,21)=21.94, p=.001, \eta_{\mathrm{p}}{ }^{2}=0.511$, for Experiment 1 and $F(1,22)=40.39, p<.001, \eta_{\mathrm{p}}{ }^{2}=0.647$, for Experiment 3, (b) for words than for nonwords, $F(1,21)=54.64, p$ $=.001, \eta_{\mathrm{p}}{ }^{2}=0.722$, for Experiment 1 and $F(1,22)=44.89, p<.001$, $\eta \mathrm{p}^{2}=0.671$ for Experiment 3, and (c) for targets at the 2nd than the 5th position, $F(1,21)=24.83, p=.001, \eta_{\mathrm{p}}{ }^{2}=0.542$, for Experiment 1 and $F(1,22)=61.78, p<.001, \eta_{\mathrm{p}}{ }^{2}=0.737$ for Experiment 3. For Experiment 1, there was no significant two-way interactions, $F(1,21)$ $\leq 2.1, p \geq .160$, whereas for Experiment 3, the interaction between visual field and target position was significant $F(1,22)=10.00, p=$ $.005, \eta_{\mathrm{p}}^{2}=0.313$.

\section{Discussion}

The experiment again demonstrated shorter RTs and better accuracy for words compared to nonwords. This result is consistent with the results of both Experiment 12 . The mean RT to targets in the LVF was shorter as compared to the RVF. This result is consistent with the result of Experiment 1, which we explained by the left-to-right reading habit.

However, target position interacted with visual field in Experiment 3, but not in Experiment 1. Also, lexicality in the RVF interacted with target position in Experiment 1, but not in Experiment 3. Overall, this result provides the same type of search regardless of stimulus type in Experiment 3. The significant effect of target position in the RVF provides evidence for a letter-by-letter search. This type of search in Experiment 3 may be explained by lexicality priming. The overall pattern of results suggests that the search typically begins in the LVF. In the trials containing a word in the RVF, the LVF contained a nonword. The participant starts searching in the LVF and then proceeds to the RVF, with his/her visual system being primed to process a letter string of the same type as was in the LVF. Then it might be assumed that the search strategy remains the same in spite of the string type switch, and single letters become processing units in the search in the RVF instead of words, which leads to the letter by letter analysis of lexical strings.

At the same time, within nonwords in the RVF, the search was carried out in the letter-by-letter manner. This search was not influenced by set. It seems to be impossible to apply a specialized left-hemisphere search strategy for words to nonwords, opposite to our earlier rapid serial visual presentation studies, where we found a "word-reading" strategic effect upon random letter strings presented letter by letter at the same central location (Falikman, 2011).

\section{GENERAL DISCUSSION}

The present study investigated visual search for letters embedded in letter strings in the left and right visual hemifields under central fixation. In accordance with the hemispheric asymmetry in lexical information processing, we expected to observe a holistic processing of a word presented in the RVF and a letter-by-letter search within a word presented in the LVF. In the Experiment 1, two letter strings were presented on both sides from the fixation and were of the same type (either Russian words or nonwords). The RT data provide evidence for the letter-by-letter search within a word in the LVF and within a nonword in the RVF, as well as for the simultaneous access to all letters within a nonword in the LVF and within a word in the RVF. We consider this result to reflect an interplay of brain asymmetry in lexical processing and specific hemispheric strategies of information processing. Although a holistic visual word processing mechanism has been described for the right hemisphere (Voyer, 2003), its effects seem to be limited to familiar high-frequency words, whereas all words used in our study belonged to the mid-frequency range, providing for the above-mentioned differences in visual search for a target letter.

This result is also partly inconsistent with the results of some previous studies, for example, Lavidor and Bailey (2005) discovered posi- 
tion effects for words in the RVF in a letter search task. In their study, a single lateralized letter string was present in the entire visual field, analogously to the manipulation we used in our Experiment 2. The results of Experiment 2 provide evidence for the letter-by-letter search regardless of the visual hemifield and string type, in agreement with the results of Lavidor and Bailey.

One more factor contributing to the mode of processing employed by the visual system when two letter strings are simultaneously present in the visual field could be lexicality priming, providing for an observer's readiness to process a letter string of a certain type (a word). The left-to-right reading strategy could induce such influence of the letter string in the LVF on the search within the second letter string in the RVF, but not vice versa.

In Experiment 3, we tested the hypothesis that a letter string in the LVF could influence the processing of the other letter string in the LVF. Two letter strings were presented on both sides from the fixation, as in Experiment 1, but they were of different type (one word and one nonword). The results of Experiment 3 were mostly similar to those of Experiment 1 for the LVF, but not for the RVF. The pattern of results obtained in Experiment 3 assumes that employing a specific mode of processing to the letter string in the RVF might be influenced to a certain extent by the letter string in the LVF. Interestingly, if a nonword is presented in the LVF, a word in the RVF does not benefit from the hemispheric asymmetry any more. However, a word in the LVF does not induce a more efficient search within a nonword in the RVF. Thus, the left hemisphere specialization would modify the search mode only within words (orthographically regular strings) and only when the visual system is primed to process words.

Taken together, the results of these experiments demonstrate how an observer chooses a search mode when searching for a letter in different types of letter strings. When just one letter string is presented to either visual field (Experiment 2), a default letter-by-letter search mode is employed regardless of the string type and visual hemifield. When both hemifields are involved (Experiments 1 and 3, two letter strings to the left and right of the fixation), a certain search mode is applied depending on the visual hemifield and the target letter string type. It seems to makes sense to spend effort and/or time to apply a certain search mode only when letter strings containing a potential target are present in both hemifields. Otherwise the search mode set-up or switch is not necessary, probably because it requires more effort and/ or time than the default use of the less efficient letter-by-letter search mode. Thus, the estimation of the visual system load, or a number of peripheral stimuli to be processed seems, to precede the search mode choice in the visual search for a letter embedded in a letter string.

Our results provide a new explanation for the results of Lavidor and Bailey's (2005). The authors assume that letter-level processing (applied in the letter search task) is similar in both hemifields, but whole-word processing is different in the left and right hemispheres. Our results rather favor a variety of letter processing strategies. The holistic search mode emerges only when both visual hemifields are involved. We believe that the use of different processing modes is associated not with the letter- or whole-word level of processing, but with the interaction of the involvement of visual hemifields and lexicality.

At the same time, our procedure does not rule out the possibility of overt shifts of attention because eye movements were not tracked in the three experiments. In our previous study, we did use eye-tracking to control for the observers' central fixation in the spatial cueing paradigm with the same layout (Gorbunova \& Falikman, 2012) and the participants were shown to successfully follow the instruction to maintain fixation. However, in the visual search paradigm used in the current study, the participants also might have made a saccade to the word string in the LVF and then to the word string in the $\mathrm{RVF}^{2}$. The results of Experiment 2 do not rule out saccades to a target letter string. However, if the processing of letter strings in Experiment 1 was focal due to the sequence of fixations, we would not have found an interaction between the visual hemifield and the type of the letter string (word vs. nonword).

Two more versions of eye movements, which were explicitly prohibited in the instruction, seem implausible. If the observers successfully maintained central fixation while performing the search in the LVF due to the left visual field advantage in left-to-right readers ${ }^{3}$, and then made a saccade to the RVF, the results of Experiment 1 should have been treated as reflecting a difference between peripheral (LVF) and focal letter string processing. In this case, there might still be a lexicality priming effect in Experiment 1 . However, the pattern of eye movements should have changed in Experiment 2 either to maintaining a fixation or to making a saccade to a letter string in either visual hemifield. Otherwise, we cannot explain symmetric RT graphs in this experiment. However still, in this case the pattern of the RVF slopes from Experiments 1 and 2 would hardly differ, and the only difference should be the delay due to the LVF string processing.

The third option is that the observers performed a saccade to the left, which provided for the focal search in the left part of the screen, and did not make any further eye movements. In this case, eccentricity would have been too high in the RVF to avoid crowding. This allows us to completely dismiss this possibility.

In conclusion, we found that in letter search within words and nonwords, visual search mode depends on the visual hemifield to which the target letter is presented, but this dependence is mediated by the presence of another letter string in the opposite visual hemifield and by the observer's readiness to process a word rather than a random letter string. These results suggest that there are at least three conditions in which a target letter embedded in a word would benefit from simultaneous access to all letters within this word: (a) its presentation to the right visual hemifield, (b) the presence of a concurrent string in the left visual hemifield, and (c) an observer's readiness to encounter a word rather than a random letter string. Also, as in a previous study of multiple object tracking (Drew et al., 2014), we might state that visual search task performance cannot be controlled at the level of separate hemispheres. This explains why different search modes can be observed both in two hemifields with the same type of letter strings and in the same hemifield with different (lexical and nonlexical) letter strings. However, further studies are necessary to better understand search asymmetries in lexical stimuli. 


\section{FOOTNOTES}

${ }^{1}$ The dictionary by Lyashevskaya \& Sharov is available online at: http://dict.ruslang.ru/freq.php

${ }^{2}$ We thank an anonymous Reviewer 2 for continuously drawing our attention to this possibility.

${ }^{3}$ We thank Alex Holcombe for drawing our attention to this possibility.

\section{REFERENCES}

Alvarez, G. A., \& Cavanagh, P. (2005). Independent resources for attentional tracking in the left and right visual hemifields. Psychological Science, 16, 637-643. doi:10.1111/j.14679280.2005.01587.x x

Alvarez, G. A., Gill, J., \& Cavanagh, P. (2012). Anatomical constraints on attentional selection: hemifield independence is a signature of multifocal spatial selection. Journal of Vision, 12, 1-20. doi:10.1167/12.5.9 المسلس

Barber, H. A., Ben-Zvi, S., Bentin, S., \& Kutas, M. (2011). Parafoveal perception during sentence reading? An ERP paradigm using rapid serial visual presentation (RSVP) with flankers. Psychophysiology, 48, 523-531. doi:10.1111/j.14698986.2010.01082.x السلسلسل

Bever, T. G. (1975). Cerebral asymmetries in humans are due to the differentiation of two incompatible processes: holistic and analytic. Annals of the New York Academy of Sciences, 263, 251-262. doi:10.1111/j.1749-6632.1975.tb41589.x السلسلسلس

Chakravarthi, R., \& Cavanagh, P. (2009). Bilateral field advantage in visual crowding. Vision Research, 49, 1638-1646. doi:10.1016/j.

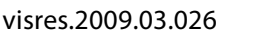

Corbetta, M., Shulman, G. L., Miezin, F. M., \& Petersen, S. E. (1995, November). Superior parietal cortex activation during spatial attention shifts and visual feature conjunction. Science, 270, 802-805. doi:10.1126/science.270.5237.802 المبلسلسلة

Corbetta, M., Miezin, F. M., Shulman, G. L., \& Petersen, S. E. (1993). A PET study of visuospatial attention. The Journal of Neuroscience, 13, 1202-1226. doi:10.1523/JNEUROSCI.13-03-01202.1993 الس

Drew, T., Mance, I., Horowitz, T. S., Wolfe, J. M., Vogel, E. K. (2014) A soft handoff of attention between cerebral hemispheres. Current Biology, 24, 1133-1137. doi:10.1016/j.cub.2014.03.054 الس

Ellis, A. W., Young, A. W., \& Anderson, C. (1988). Modes of word recognition in the left and right cerebral hemispheres. Brain and Language, 35, 254-273. doi:10.1016/0093-934X(88)90111-3 الس السلس

Falikman, M. (2002). Word preference effect and the attentional blink: Who will have the upper hand? In E. Van der Meer, $\mathrm{H}$. Hagendorf, R. Beyer, F. Krueger, A. Nuthmann, \& S. Schultz (Eds.), Proceedings of the forty-third congress der Deutschen gesellschaft fur psychologie (p. 324). Lengerich, Germany: Pabst Science Publishers.

Falikman, M. (2011). Word superiority effects across the varieties of attention. Journal of Russian and East European Psychology,

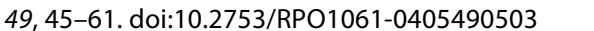

Fine, E. M. (2001). Does meaning matter? The impact of word knowledge on lateral masking. Optometry and Vision Science, 78, 831-838. doi:10.1097/00006324-200111000-00013 المالسلسلس

Gorbunova, E., \& Falikman, M. (2010). Word superiority within the attentional blink. Journal of Vision, 10, 203. doi:10.1167/10.7.203 سلس

Gorbunova, E., \& Falikman, M. (2012). Visual search for letters within words and nonwords in the right and left visual hemifields. Perception, 41, Abstract Supplement, 143.

Husain, M., Shapiro, K., Martin, J., \& Kennard, C. (1997). Abnormal temporal dynamics of visual attention in spatial neglect patients. Nature, 385, 154-156. doi:10.1038/385154a0 المبلسليلكا

Johnson, N. F., \& Carnot, M. J. (1990). On time differences in searching for letters in words and nonwords: Do they emerge during the initial encoding or the subsequent scan? Memory \& Cognition, 18, 31-39. doi:10.3758/BF03202643 السلسلسلس

Johnston, J. C., \& McClelland, J. L. (1974, June). Perception of letters in words: Seek not and ye shall find. Science, 184, 11921194. doi:10.1126/science.184.4142.1192 المالسلسليا

Jordan, T. R., Patching, G. R., \& Milner, A. D. (2000). Lateralized word recognition: Assessing the role of hemispheric specialization, modes of lexical access and perceptual asymmetry. Journal of Experimental Psychology: Human Perception and Performance, 26, 1192-1208. doi:10.1037//0096-152326.3.1192 المالسلس الس

Kimchi, R. (2015) The perception of hierarchical structure. In: J. Wagemans (Ed.), Oxford handbook of perceptual organization (pp. 129-149). Oxford, England: Oxford University Press.

Kimchi, R., \& Merhav, I. (1991). Hemispheric processing of global form, local form, and texture. Acta Psychologica, 76, 133-147. doi:10.1016/0001-6918(91)90042-X Xلس الس

Krueger, L. E., Keen, R. H., \& Rublevich, B. (1974). Letter search through words and nonwords by adults and fourth-grade children. Journal of Experimental Psychology, 102, 845-849. doi:10.1037/h0036332 الس الس

Lavidor, M., \& Bailey, P. (2005). Dissociations between serial position and number of letters effects in lateralised visual word recognition. Journal of Research in Reading, 28, 258-273. doi:10.1111/j.1467-9817.2005.00269.x المالسلس

Levine, S. C., \& Koch-Weser, M. P. (1982). Right hemisphere superiority in the recognition of famous faces. Brain and Cognition, 1, 10-22. doi:10-2210.1016/0278-2626(82)90003-3 سلس

Lindell, A. K. (2006). In your right mind: Right hemisphere contributions to language processing and production. Neuropsychology Review, 16, 131-148. doi: 10.1007/s11065006-9011-9

Luck S. J., Hillyard S. A., Mangun G. R., \& Gazzaniga M. S. (1989). Independent hemispheric attentional systems mediate visual search in split-brain patients. Nature, 342, 543-545.

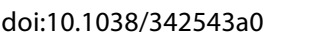

Luiga, I., Bachmann, T., \& Põder, E. (2002). Metacontrast masking of single letters in words and trigrams with varying loads on attention. Perception, 31, ECVP Abstract Supplement, 79. |لس

Madrid, G. J., Lavie, N., \& Lavidor M. (2010). Asymmetrical 
perceptual load in lateralised word processing. European Journal of Cognitive Psychology, 22, 1066-1077.

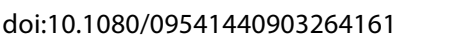

Michael, G. A., \& Ojeda, N. (2005). Visual field asymmetries in selective attention: Evidence from a modified search paradigm. Neuroscience Letters, 388, 65-70. doi:10.1016/j.neu-

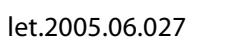

Navon, D. (1977). Forest before trees: The precedence of global features in visual perception. Cognitive Psychology, 9, 353-383. doi:10.1016/0010-0285(77)90012-3 سلس

Pantyushkov, A., Horowitz, T. S., \& Falikman, M. V. (2008). Is there word superiority in visual search? In Third international conference on cognitive science: Book of abstracts (Vol. 1, pp. 124-125). Moscow, Russia

Pechenkova, E. \& Sinitsyna, M. (2009). Top-down modulations in perception of simultaneity. Journal of Vision, 9, 1083. doi:10.1167/9.8.1083 الس الس الس

Potter, M. C., Nieuwenstein, M., \& Strohminger, N. (2008). Whole report versus partial report in RSVP Sentences. Journal of Memory and Language, 58, 907-915. doi:10.1016/j. jml.2007.12.002 سلسلس

Reardon K. M., Kelly J. G., \& Matthews N. (2009). Bilateral attentional advantage on elementary visual tasks. Vision Research,

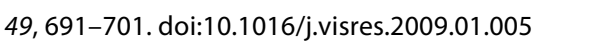

Reicher, G. M. (1969). Perceptual recognition as a function of meaningfulness of stimulus material. Journal of Experimental Psychology, 81, 275-280. doi:10.1037/h0027768 الس السلسلس

Salvemini, A. V., Stewart, A. L., Purcell, D. G., \& Pinkham, R. S.
(1998). A word-superiority effect in the presence of foveal load. Perceptual and Motor Skills, 86, 1311-1319. doi: 10.2466/ pms.1998.86.3c.1311 سلسلس

Scott, G. B., \& Hellige, J. B. (1998). Hemispheric asymmetry for word naming: effects of frequency and regularity of pronunciation. Laterality, 3, 343-371. doi:10.1080/713754310 السلسلس

Starrfelt, R., Petersen, A., \& Vangkilde, S. (2013). Don't words come easy? A psychophysical exploration of word superiority. Frontiers in Human Neuroscience, 7, 519. doi:10.3389/fnhum.2013.00519 سلس سل

Tadros K., Dupuis-Roy N., Fiset D., Arguin M., \& Gosselin F. (2013). Reading laterally: the cerebral hemispheric use of spatial frequencies in visual word recognition. Journal of Vision, 13. doi:10.1167/13.1.4 سلس

Turkovsky, A. A., Bespalov, B. I., Vartanov, A. V., \& Kiselnikov, A. A. (2014). Evaluation of the instrumental error in a chronometric psychological experiment using modern equipment. Psychology Journal of Higher School of Economics, 11, 166-176. السلسلسل| Wheeler, D. D. (1970). Processes in word recognition. Cognitive Psychology, 1, 59-85. doi:10.1016/0010-0285(70)90005-8 الس الس الس Voyer D. (2003). Word frequency and laterality effects in lexical decision: Right hemisphere mechanisms. Brain and Language, $87,421-431$. الس السلسل

Whitney, C. \& Lavidor, M. (2004). Why word length only mat-

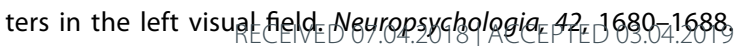

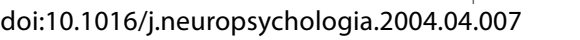

Wojciulik, E., \& Kanwisher, N. (1999) The generality of parietal involvement in visual attention. Neuron, 24, 747-764. doi:10.1016/S0896-6273(01)80033-7 (ل) 